\title{
Posterior lenticonus with involvement of foetal nucleus
}

\author{
DALJIT SINGH AND DHANWANT SINGH \\ Department of Ophthalmology, Government Medical College, Patiala, India
}

Posterior lenticonus is a prominent spheroid elevation occurring on the posterior surface of the lens. Since the first case was observed by Meyer (1888: see Duke-Elder, 1964), some hundred cases have been reported. The condition is usually complicated by the presence of posterior polar lens opacities, which may be dust-like, trumpet-shaped, rosettelike, or in reduplicated forms resembling a collar-stud. These disturbances have been seen to involve only the outer zones of discontinuity, without disturbing the foetal or embryonal nucleus. A case of posterior lenticonus is reported below, in which a tubeshaped opacity extended from the globus area into the lens and involved the posterior half of the foetal nucleus.

\section{Case report}

A r3-year-old girl came to the clinic with the complaint of poor vision in the right eye since birtto Before the pupil was dilated, a posterior lenticular opacity with a curious dark circular area could be seen. After dilatation ophthalmoscopic examination revealed the typical circular ring reflex of posterior lenticonus. Slit-lamp examination showed the lenticonus to be limited to about $1.5 \mathrm{~mm}$. diameter in the middle of the posterior surface of the lens. A white tube-shaped opacity of granular texture was found to extend from the area of lenticonus into the substance of the lens for a considerable distance $(2.5$ to $3 \mathrm{~mm}$.). The cavity of the tube appeared to be empty. The outer end of the tube was opaque as were the sides.

Optical section revealed that, whereas the anterior $\mathrm{Y}$-suture was plainly visible, the posterior $X$-suture could not be found, nor could we find the posterior part of the foetal nucleus, the place of both these structures being occupied by the empty space inside the tube-shaped opacity. Remnants of the hyaloid vessels could be faintly seen on the back of the globe. The Figure shows details of the lenticonus and opacity in section. The anterior end of the opacity was expanded. The circular reflex was caused by the zone of specular reflection at the place where the capsule makes a sudden turn in the frontal plane.

Retroillumination showed that the disturbance in the lens was even more extensive, being about $\frac{D}{O}$ four times the area of the lenticonus. This abnormal area was sharply delineated from the normal lens substance. Just below and lateral to the lenticonus the capsule had the appearance of $\mathcal{N}$ crocodile skin, and beside it was a sickle-shaped area of a uniform dark appearance.

The corrected visual acuity was $5 / 60$, with $+1 \cdot 5 \mathrm{D}$ sph., and there was a divergent squint of $15^{\circ}$.

\section{Comment}

The causation of lenticonus is a matter of controversy. The widespread disturbances in $\stackrel{\mathscr{\infty}}{\rightarrow}$ the lens and lens capsule beyond the area of the lenticonus in this case suggest that the malformation was due to the herniation of lens substance through a weakened capsule. 


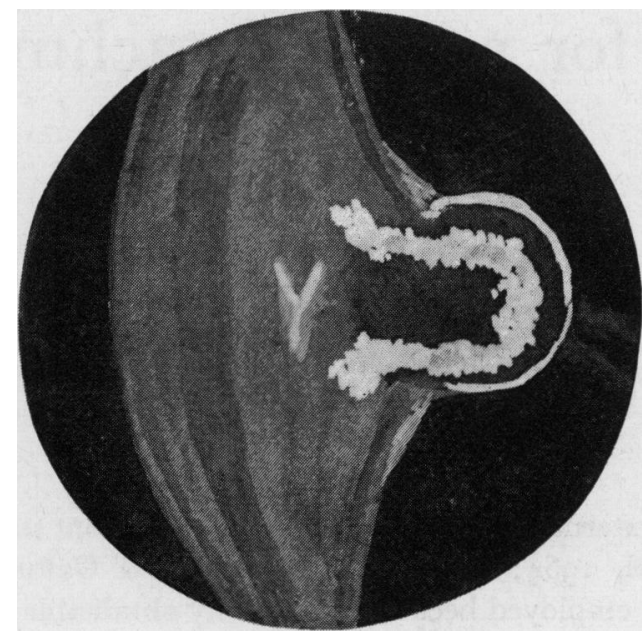

FIGURE Optical section, showing anterior $r$-suture and tube-like opacity

\section{Summary}

A case is reported of posterior lenticonus with a tube-like opacity running from the dorsal bulge anteriorly, enclosing an optically empty space and involving the posterior $\mathrm{X}$-suture and foetal nucleus.

\section{References}

DUKE-ELDER, S. (1964) "System of Ophthalmology", vol. 3, pt 2, p. 700. Kimpton, London MEYER, F. (1888) Zbl. prakt. Augenheilk., 12, 4I 